\title{
Pili Annulati and Trichorrhexis Nodosa in the Same Patient: Cause or Coincidence?
}

\author{
Aline Donati Anna Cecília Andriolo Marina Barletta Neusa Valente \\ Ricardo Romiti \\ Department of Dermatology, University of São Paulo, São Paulo, Brazil
}

\section{Established Facts}

- Pili annulati (PA) is a hereditary hair shaft disorder not usually related to increased hair fragility.

- Acquired trichorrhexis nodosa is the hallmark of hair weathering.

- Six cases of PA and increased hair fragility have been published in the English literature, suggesting increased stiffness of darker bands or associated cuticular damage.

\section{Novel Insights}

- Greater stiffness of the darker bands was excluded in this case because breakage did not occur only in dark bands.

- A personal history of hypothyroidism, thin hairs and a family history of hair fragility might be involved in this patient.

- Cuticular damage related to PA could be associated with hair fragility.

\section{Key Words}

Hair - Hair care · Hair cosmetics · Hair disorder · Hair microscopy · Pili annulati

\section{Abstract}

Purpose: To determine the relationship between pili annulati (PA) and acquired trichorrhexis nodosa (TN) seen in the same patient, considering the two main theories evoked by previous studies: greater stiffness of darker PA bands or associated cuticular damage. Procedures: Light microscopy of hair shafts from different regions of the patient's scalp. $\boldsymbol{R e}$ sults: TN was not superimposed to dark bands of PA. Conclusions: Greater stiffness of darker PA bands was excluded as the cause of hair breakage. Hair breakage in PA patients might be related to cuticular abnormalities, as previously reported. Because weathering of long thin chemically treated hairs is extremely common, coincidence cannot be completely ruled out in this case.

(c) 2015 S. Karger AG, Basel

\section{Introduction}

Pili annulati (PA) is a hereditary hair shaft disorder not usually related to increased hair fragility [1]. Acquired trichorrhexis nodosa (TN) is the hallmark of hair weathering and affects mainly women with long and thin hairs

\section{KARGER 125}

E-Mail karger@karger.com www.karger.com/sad
(C) 2015 S. Karger AG, Base

2296-9195/15/0011-0025\$39.50/0
Aline Donati

Alameda Rio Claro, 157/121 Bela Vista

São Paulo, SP 01332-010 (Brazil)

E-Mail aline@donati.com.br 


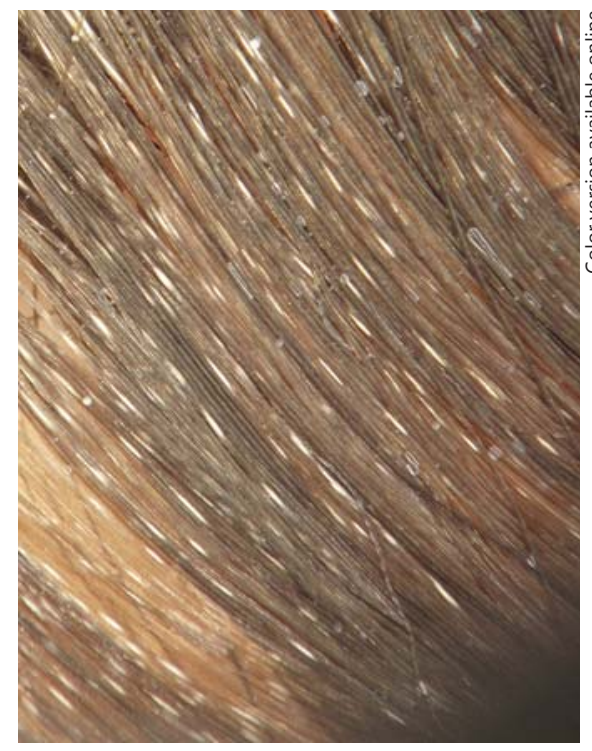

Fig. 1. Dermoscopy of hairs in the temporal area showing typical findings of PA with alternate light bands in some hair shafts (video dermoscopy, $\times 32$ ).

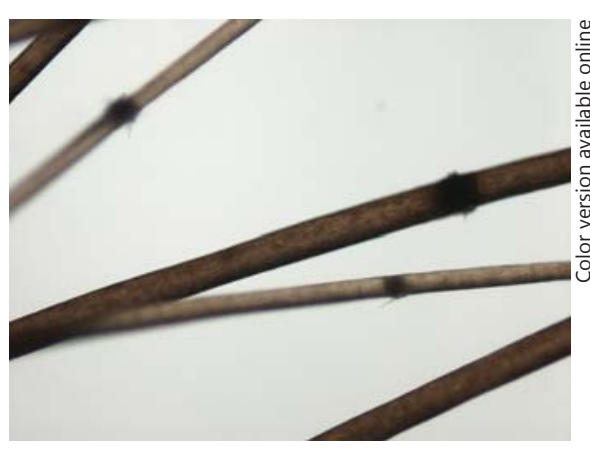

Fig. 2. Typical TN affecting hairs from the patient's occipital area (light microscopy, $\times 100)$.

4

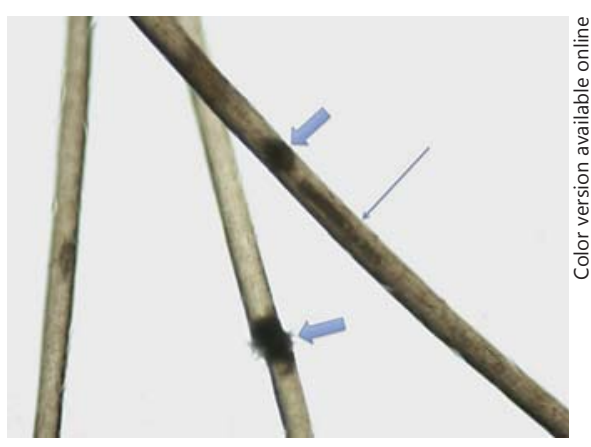

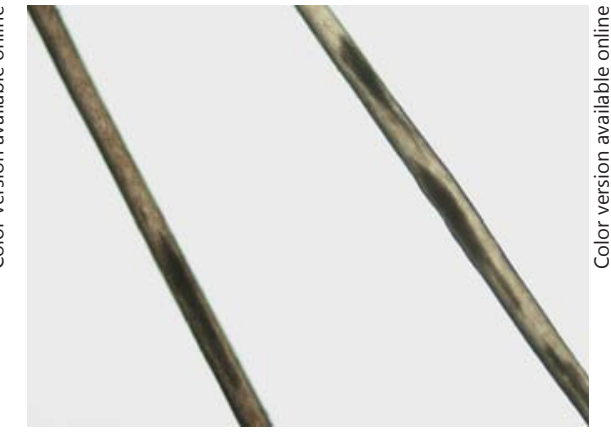

Fig. 3. PA findings on hairs from the patient's temporal region of the scalp (light microscopy, $\times 100$ ).
5

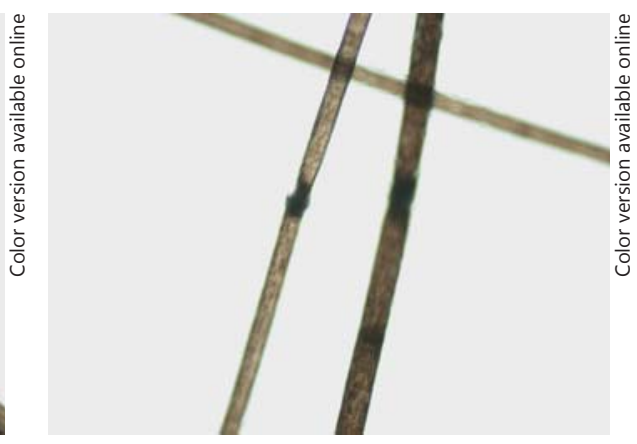

Fig. 4. $P A$ and $T N$ affecting hairs from the patient's occipital area. Note that hair breakage (large arrows) occurs independently of air-filled cavities (thin arrow) (light microscopy, $\times 100$ ).

Fig. 5. TN affecting hairs from the patient's father (light microscopy, $\times 100$ ).

who use heat and chemical products for hair care [2, 3]. We report the case of a young woman with PA that presented with TN and short hairs in the occipital area and discuss whether there is any causal relationship between PA and increased hair fragility.

\section{Case Report}

A 22-year-old Caucasian woman complained of thin and brittle hair since puberty. The occipital area was particularly affected with hairs shorter than those in the rest of the scalp. Bleaching was performed twice in the last 8 months and she blew dried her hair on a daily basis. Her personal history included hypothyroidism treated since the age of 12 . Her father also had short and thin hairs.
On physical examination, short $(5 \mathrm{~cm}$ long) shafts with broken ends were seen in the occipital area. The rest of the scalp showed thin, light brown and shoulder-length hairs. Alternate light and dark banding was better observed on bleached hairs at the frontal and lateral sides of the scalp (fig. 1). Only few hairs with alternate banding were found among broken hairs on the occipital area. Hairs in other skin regions were not affected. The rest of the skin as well as teeth and nails showed no abnormality.

Hair samples from the patient's temporal and occipital areas were examined under conventional light microscopy. Irregularly spaced dark cavities were observed on hairs from the temporal area (fig. 2) confirming the diagnosis of PA, while hairs from the occipital area showed brush-like figures (fig. 3) confirming the hypothesis of TN. Interestingly, whenever PA and TN were found in the same shaft, they did not necessarily occur in the same spot (fig. 4). 
Since PA is a hereditary disorder, microscopic examination of the hair shafts of the patient's parents was also performed and detected TN on the father's hair, but no signs of PA involvement in either parent (fig. 5).

The patient was diagnosed with PA and increased hair fragility. She was advised to avoid any form of hair treatment with chemicals or heat devices and to increase hair conditioning. Vitamins were prescribed to increase the hair strength.

\section{Discussion}

PA is a hair shaft disorder characterized by alternate bands of light and dark areas within the shaft $[1,2]$. Not all hairs are affected and the same follicle may present intermittent involvement. Even though PA is classically not associated with increased hair fragility, a review of the English literature revealed 6 cases of PA and increased hair fragility $[1,2,5,6]$, and two different theories have emerged to explain these cases.

In 2007, the examination of PA shafts with atomic force microscopy showed increased stiffness of darker bands compared to lighter ones [4]. Variations in amino acid composition could explain this mechanical difference between PA bands and could lead to a greater chance of breakage of darker bands using light microscopy [4].

Two different studies $[5,6]$ detected cuticular damage in shafts with PA by using scanning electron microscopy.
The cause of this finding as well as the origin of the cavities themselves are not known, but this abnormality could explain an increased susceptibility to weathering of PAaffected shafts.

In our case, both PA and hair breakage were observed in the same patient. However, TN was not present only in PA-affected hairs and it did not occur only in dark bands, so it seems that breakage was not related to a possible greater stiffness over the darker bands. Cuticular damage due to PA, if real, could add to the patient's personal history of hypothyroidism, thin hairs and family history of hair fragility and lead to an increased susceptibility to weathering.

\section{Conclusion}

Hair breakage in PA patients might be related to cuticular abnormalities, as previously reported. Because weathering of long thin chemically treated hairs is extremely common, coincidence cannot be completely ruled out in this case.

\section{Disclosure Statement}

The authors have no sponsorship, funding arrangements or conflicts of interest to disclose relating to this article.

\section{References}

Pili Annulati and Trichorrhexis Nodosa in the Same Patient
1 Werner K, St-Surin-Lord S, Sperling LC: Pili annulati associated with hair fragility: cause or coincidence? Cutis 2013;91:36-38.

- 2 Giehl KA, Ferguson DJP, Dawber RPR, et al: Update on detection, morphology and fragility in pili annulati in three kindreds. Eur Acad Dermatol Venereol 2004;18:654-658.

-3 Osório F, Tosti A: Pili annulati - what about racial distribution? Dermatol Online J 2012; 18:10.

4 Streck AP, Moncores M, Sarmento DF, et al: Study of nanomechanical properties of hu- man hair shaft in a case of pili annulati by atomic force microscopy. J Eur Acad Dermatol Venereol 2007;21:1109-1110.

-5 Akoglu G, Emre S, Metin A, Erbil KM, et al: Pili annulati with fragility: electron microscopic findings of a case. Int J Trichology 2012;4:89-92.

6 Feldmann KA, Dawber RP, Pittelkow MR, Ferguson DJ: Newly described weathering pattern in pili annulati hair shafts: a scanning electron microscopic study. J Am Acad Dermatol 2001;45:625-627. 